\title{
Inducible Clindamycin Resistance in Staphylococcus aureus Isolated from Nursing and Pharmacy Students
}

\author{
Renushri, Avinandan Saha, Nagaraj, Veena Krishnamurthy
}

Department of Microbiology, Sri Siddharta Medical College, Tumkur, Karnataka, India

Address for correspondence: Dr. Renushri, E-mail: dr.renushree@gmail.com

\section{ABSTRACT}

Aims: Emergence of resistant isolates of Staphylococcus aureus (S. aureus) has resulted in failure of clindamycin therapy. The prevalence of inducible clindamycin resistance in S. aureus isolated from nursing students and pharmacy students (representing carriers exposed and not exposed to hospital environment respectively) was evaluated.

Materials and Methods: Nasal, throat, and palmar swabs were collected from 119 nursing students and 100 pharmacy students. S. aureus was identified and antibiogram obtained by Clinical and Laboratory Standards Institute guidelines. Inducible clindamycin resistance was detected by the D-test.

Results: 36 and 34 individuals in the exposed and non-exposed groups respectively were carriers of S. aureus. 16.7\% and $5.9 \%$ isolates showed inducible clindamycin resistance in exposed and non-exposed groups, respectively. The percentage of inducible clindamycin resistance was higher among methicillin-resistant S. aureus (MRSA) (27.8\%) compared to methicillin-sensitive S. aureus (5.8\%).

Conclusion: $S$. aureus isolates resistant to $\beta$-lactams can also show inducible clindamycin resistance. Exposure to hospital environment was not found to be a risk factor for carriage of $S$. aureus with MLSBi phenotype.

Keywords: Inducible clindamycin resistance, MLSBi phenotype, MRSA, S. aureus carriers

\section{INTRODUCTION}

lindamycin, an antimicrobial belonging to the macrolide-lincosamide-streptogramin B (MLS $\left.{ }_{\mathrm{B}}\right)$ family, is frequently used for treatment of skin and soft tissue infections caused by Staphylococcus aureus (S. aureus). However, the widespread use of the $\mathrm{MLS}_{\mathrm{B}}$ family of antimicrobials has led to the emergence of resistance. ${ }^{[1]}$ The common mechanism of resistance is mediated by erm genes that encode enzymes conferring inducible $\left(\mathrm{MLS}_{\mathrm{B}} \mathrm{i}\right)$ or constitutive $\left(\mathrm{MLS}_{\mathrm{B}} \mathrm{c}\right)$ resistance to $\mathrm{MLS}_{\mathrm{B}}$ agents by reducing binding by these agents to the bacterial ribosome. ${ }^{[2-4]}$

Isolates with inducible clindamycin resistance are found to be resistant to erythromycin but susceptible to clindamycin when these discs are not placed

\begin{tabular}{|l|l|}
\multicolumn{3}{c}{ Access this article online } \\
\hline Quick Response Code: & Website: \\
\hline & www.jponline.org \\
\hline & \\
\hline
\end{tabular}

adjacent to each other during antimicrobial sensitivity testing. Consequently, laboratory identification of such isolates is often missed, resulting in inappropriate therapeutic use of clindamycin and treatment failure. ${ }^{[2]}$ These isolates can be detected by the D-test, a disc diffusion test in which induction of clindamycin resistance by erythromycin is tested. ${ }^{[2,5,6]}$

S. aureus can colonize healthy community-dwelling individuals, who are not only at an increased risk for developing subsequent infections, but also transmit the pathogen to other individuals..$^{[7-9]}$ Methicillinresistant $S$. aureus (MRSA) is an important nosocomial pathogen and healthcare professionals, who are known to be carriers of MRSA, can transmit the pathogen to patients under their care, thereby leading to various complications associated with MRSA infections (like pneumonia and septicemia) in the patients. ${ }^{[7]}$

In this study, the prevalence of inducible clindamycin resistance in $S$. aureus isolated from nursing students and pharmacy students (representing carriers exposed and not exposed to hospital environment, respectively) was evaluated, with particular regard to MRSA. 


\section{MATERIALS AND METHODS}

The present study was conducted at the department of microbiology of our medical college from 30 June, 2010 to 31 August, 2010. Institutional ethical committee approval was obtained.

One hundred nineteen students of the age group 18-23 years of the college of nursing attached to our hospital were included in the study. All students attended rotating sessions for at least $4 \mathrm{~h}$ daily in various hospital departments for the last 6 months. They represented the group exposed to hospital environment.

One hundred age-matched students of the college of pharmacy in our city were also studied. None of the students in this group had a history of hospitalization or regular visits to a hospital in the last 6 months. They represented the group not exposed to hospital environment.

None of the subjects had a history of illness or treatment with an antibiotic in the last 6 months. An informed written consent was obtained from each of the subjects.

Nasal, throat, palmar, and web-space swabs were collected from each of the subjects. S. aureus was identified phenotypically by growth on mannitol salt agar, Gram's stain, catalase test, and slide and tube coagulase tests. $^{[10-12]}$ Antimicrobial susceptibility testing of the isolates to penicillin (10 U), cefoxitin $(30 \mu \mathrm{g})$, erythromycin $(15 \mu \mathrm{g})$, and clindamycin $(2 \mu \mathrm{g})$ (HiMedia, Mumbai) was carried out by the standard disc diffusion test as per Clinical and Laboratory Standards Institute (CLSI) guidelines. ${ }^{[13]}$ The erythromycin and clindamycin discs were placed $15 \mathrm{~mm}$ apart edge to edge. ${ }^{[2,5]}$

Isolates showing resistance to erythromycin (zone size $\leq 13 \mathrm{~mm}$ ) and sensitivity to clindamycin (zone size $\geq 21 \mathrm{~mm}$ ), as well as giving a D-shaped zone of inhibition around clindamycin with flattening adjacent to the erythromycin disc were considered to show inducible clindamycin resistance [Figure 1]. ${ }^{[5,6]} S$. aureus BAA 977 and S. aureus BAA 976 were used as the positive and negative controls, respectively.

MRSA was detected by the cefoxitin disc diffusion test, using a $30 \mu \mathrm{g}$ disc (HiMedia, Mumbai) (an inhibition zone diameter of $\leq 21 \mathrm{~mm}$ was reported as oxacillin or methicillin resistant and a zone diameter of $\geq 22 \mathrm{~mm}$ was considered sensitive) and by growth on oxacillin screen agar, incorporating $4 \% \mathrm{NaCl}$ and $6 \mu \mathrm{g} / \mathrm{ml}$ of oxacillin (HiMedia, Mumbai), as per CLSI guidelines. ${ }^{[12-14]}$

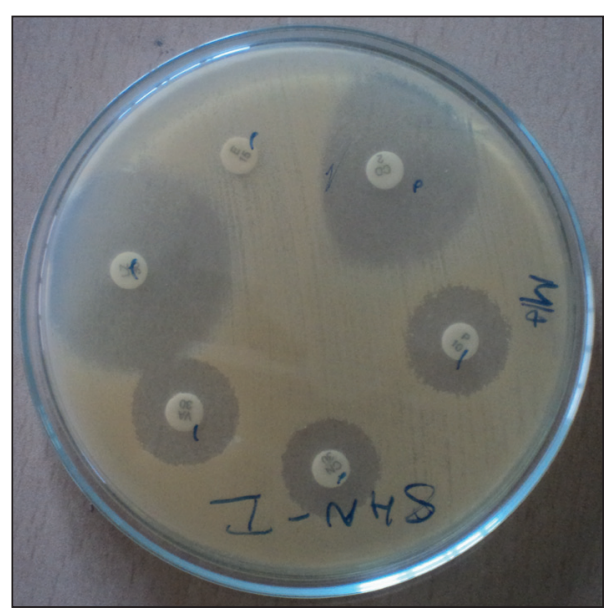

Figure 1: D-test showing a blunted zone of inhibition around the clindamycin disc adjacent to the erythromycin disc

Quality control strains-MRSA ATCC 43300 and methicillin-sensitive $S$. aureus (MSSA) ATCC 25923-were used as positive and negative controls, respectively.

Association of exposure to hospital environment with carriage of $S$. aureus showing $\mathrm{MLS}_{\mathrm{B}} \mathrm{i}$ phenotype, and association between methicillin resistance and expressionof $\mathrm{MLS}_{\mathrm{B}} \mathrm{i}$ phenotype were evaluated using the chi-square $\left(\chi^{2}\right)$ test.

\section{RESULTS}

In the exposed group, 36 individuals were found to be carriers of $S$. aureus. Isolates from six (16.7\%) individuals showed inducible clindamycin resistance. From the nonexposed group, 34 individuals were found to be carriers of $S$. aureus. Isolates from two $(5.9 \%)$ individuals showed inducible clindamycin resistance.

The number of isolates showing $\mathrm{MLS}_{\mathrm{B}} \mathrm{i}$ and MS (resistance to erythromycin but sensitivity to clindamycin without forming a D-zone around the clindamycin disc) phenotypes in the groups exposed and not exposed to a hospital environment, as well as their categorization as MRSA and MSSA, is shown in [Table 1].

None of the isolates showed constitutive clindamycin resistance (MLS $\mathrm{B}$ c phenotype).

The percentage of inducible clindamycin resistance was higher among the group exposed to a hospital environment than among the group not exposed. However, this was not found to be statistically significant $\left(\chi^{2}=2.02 ; P>0.05\right)$.

The percentage of inducible clindamycin resistance was also higher among MRSA isolates compared to MSSA isolates [Table 2] and this was found to be statistically significant $\left(\chi^{2}=6.38 ; P<0.05\right)$.

Journal of Laboratory Physicians / Jul-Dec 2011 / Vol-3 / Issue-2 


\begin{tabular}{|c|c|c|c|c|c|}
\hline \multirow[t]{2}{*}{ Study group } & \multirow{2}{*}{$\begin{array}{l}\text { Total no. of carriers } \\
\text { of S. aureus }\end{array}$} & \multicolumn{2}{|c|}{ No. of isolates showing $\mathrm{MLS}_{\mathrm{B}} \mathrm{i}$ phenotype } & \multicolumn{2}{|c|}{ No. of isolates showing MS phenotype } \\
\hline & & MRSA (\%) & MSSA (\%) & MRSA (\%) & MSSA (\%) \\
\hline Exposed & 36 & $4(11.1)$ & $2(5.6)$ & $6(16.7)$ & $1(2.8)$ \\
\hline Non-exposed & 34 & $1(2.9)$ & $1(2.9)$ & $\mathrm{o}(0)$ & $5(14.7)$ \\
\hline
\end{tabular}

\begin{tabular}{|c|c|c|c|}
\hline \multicolumn{4}{|c|}{$\begin{array}{l}\text { Table 2: Number of MRSA and MSSA isolates } \\
\text { exhibiting the MLS }{ }_{B} \text { phenotype from both } \\
\text { exposed and non-exposed groups }\end{array}$} \\
\hline Nature of isolate & Total no. & $\begin{array}{c}\text { With MLS } \mathrm{S}_{\mathrm{B}} \mathrm{i} \\
\text { phenotype (\%) }\end{array}$ & $\begin{array}{l}\text { Without MLS } \mathrm{B} \\
\text { phenotype }(\%)\end{array}$ \\
\hline MRSA & 18 & $5(27.8)$ & $13(72.2)$ \\
\hline MSSA & 52 & $3(5.8)$ & $49(94.2)$ \\
\hline
\end{tabular}

Of the $36 \mathrm{~S}$. aureus isolates obtained from the group exposed to hospital environment, 13 were resistant to erythromycin; of the $34 \mathrm{~S}$. aureus isolates obtained from the non-exposed group, 7 were resistant to erythromycin.

The distribution of $S$. aureus isolated from different carriage sites is given in Table 3 .

\section{DISCUSSION}

Clindamycin provides an appropriate alternative for treatment of infections caused by isolates of $S$. aureus that are resistant to other antimicrobials like $\beta$-lactams, fluoroquinolones, and macrolides. However, isolates that are resistant to erythromycin may also show inducible resistance to clindamycin which can lead to treatment failure.

In our study, $11.4 \%$ (8 out of 70 individuals in both the study groups taken together) were colonized with $S$. aureus isolates showing the $\mathrm{MLS}_{\mathrm{B}} \mathrm{i}$ phenotype. Other Indian studies on clinical isolates of $S$. aureus showed $\mathrm{MLS}_{\mathrm{B}} \mathrm{i}$ prevalence of $14.5 \%$ and $13.1 \% \cdot{ }^{[5,15]}$ Results of studies in other countries varied considerably with MLS $_{\mathrm{B}}$ i prevalence of $25.4 \%$ and $52 \%$ being reported among $S$. aureus. ${ }^{[2,16]}$

The group exposed to a hospital environment had a larger percentage $(16.7 \%)$ of individuals colonized with $S$. aureus isolates with the MLS $\mathrm{i}$ phenotype compared to the group not exposed (5.9\%) [Table 1]. This could be attributed to the fact that antibiotic resistance is more likely to emerge among $S$. aureus isolated from a hospital due to widespread antibiotic use and the resultant selection pressure created in a hospital environment. However, we found that the association between exposure to hospital environment and acquisition of isolates with the MLS $_{B} i$ phenotype was not statistically significant. This could be attributed to the limited number of isolates with the $\mathrm{MLS}_{\mathrm{B}} \mathrm{i}$ phenotype that we obtained in our study.

\begin{tabular}{|c|c|c|}
\hline \multirow[t]{2}{*}{ Site of isolation } & \multicolumn{2}{|c|}{ Number of isolates } \\
\hline & Exposed group & Non-exposed group \\
\hline Nose & 16 & 18 \\
\hline Throat & 10 & 7 \\
\hline Web space & 1 & 7 \\
\hline Nose and throat & 3 & 1 \\
\hline Nose and web space & 4 & 1 \\
\hline Throat and web space & 2 & 0 \\
\hline Nose, throat and web space & 0 & 0 \\
\hline
\end{tabular}

More MRSA isolates showed MLS $\mathrm{i}$ phenotype (27.8\%) compared to MSSA isolates (5.8\%) [Table 2]. Our results vary a little compared to other Indian studies that reported MLS $_{B}$ i prevalence of $27.6 \%$ and $38.4 \%$ among MRSA, and $1.6 \%$ and $12.9 \%$ among MSSA. ${ }^{[5,15]}$ Association of methicillin resistance with the presence of the $\mathrm{MLS}_{\mathrm{B}} \mathrm{i}$ phenotype was found to be statistically significant in our study.

It was found that in the exposed group, most isolates showing the MS phenotype were also resistant to methicillin, whereas in the non-exposed group, all isolates showing MS phenotype were sensitive to methicillin [Table 1].

In conclusion, it is very likely that isolates of $S$. aureus resistant to $\beta$-lactams will also show inducible clindamycin resistance. Exposure to hospital environment is not found to be a risk factor for carriage of $S$. aureus with the $M_{B} S_{B} i$ phenotype. However, given that (to the best of our knowledge), this is the first study to explore the prevalence of the $\mathrm{MLS}_{\mathrm{B}} \mathrm{i}$ phenotype in $S$. aureus isolated from carriers, further evaluation with a larger sample size is required for confirmation of the existence of an association between exposure to hospital environment and carriage of $S$. aureus with the $\mathrm{MLS}_{\mathrm{B}} \mathrm{i}$ phenotype.

\section{REFERENCES}

1. Lowy FD. Antimicrobial resistance: the example of Staphylococcus aureus. J Clin Invest 2003;111:1265-73.

2. Fiebelkorn KR, Crawford SA, McElmeel ML, Jorgensen JH. Practical disk diffusion method for detection of inducible clindamycin resistance in Staphylococcus aureus and coagulase-negative staphylococci. J Clin Microbiol 2003;41:4740-4. 
3. Angel MR, Balaji V, Prakash J, Brahmadathan KN, Mathews MS. Prevalence of inducible clindamycin resistance in gram positive organisms in a tertiary care centre. Indian J Med Microbiol 2008;26:262-4.

4. Schreckenberger PC, Ilendo E, Ristow KL. Incidence of constitutive and inducible clindamycin resistance in Staphylococcus aureus and coagulasenegative staphylococci in a community and a tertiary care hospital. J Clin Microbiol 2004;42:2777-9.

5. Deotale V, Mendiratta DK, Raut U, Narang P. Inducible clindamycin resistance in Staphylococcus aureus isolated from clinical samples. Indian J Med Microbiol 2010;28:124-6.

6. Yilmaz G, Aydin K, Iskender S, Caylan R, Koksal I. Detection and prevalence of inducible clindamycin resistance in staphylococci. J Med Microbiol 2007;56:342-5.

7. Lowy FD. Staphylococcus aureus infections. N Engl J Med 1998;339:520-32.

8. Mulligan ME, Murray-Leisure KA, Ribner BS, Standiford HC, John JF, Korvick JA, et al. Methicillin-resistant Staphylococcus aureus: a consensus review of the microbiology, pathogenesis, and epidemiology with implications for prevention and management. Am J Med 1993;94:313-28.

9. Kluytmans-VandenBergh MF, Kluytmans JA. Community-acquired methicillin-resistant Staphylococcus aureus: current perspectives. Clin Microbiol Infect 2006;12 Suppl 1:9-15.

10. Forbes BA, Sahm DF, Weissfeld AS, editors. Bailey and Scott's diagnostic microbiology. $12^{\text {th }}$ ed. St. Louis, USA: Mosby Elsevier; 2007.

11. Winn WC Jr, Koneman EW, Allen SD, Procop GW, Janda WM,
Schreckenberger PC, et al, editors. Koneman's color atlas and textbook of diagnostic microbiology. $6^{\text {th }}$ ed. Baltimore (USA): Lippincott Williams and Wilkins; 2006.

12. Baird D. Staphylococcus: cluster-forming Gram-positive cocci. In: Collee JG, Marmion BP, Fraser AG, Simmons A, editors. Mackie and McCartney practical medical microbiology. 14 ${ }^{\text {th }}$ ed. New Delhi: Elsevier; 2006. p. 255.

13. Clinical and laboratory standards institute. Performance standards for antimicrobial susceptibility testing; seventeenth informational supplement. CLSI document M100-S17. Wayne Pa: CLSI; 2007.

14. Swenson JM, Patel JB, Jorgensen JH. Special phenotypic methods for detecting antibacterial resistance. In: Murray PR, Baron EJ, Landry ML, Jorgensen JH, Pfaller MA, editors. Manual of clinical microbiology. $9^{\text {th }}$ ed. Washington, DC: ASM Press; 2007. p. 1175-6.

15. Ciraj AM, Vinod P, Sreejith G, Rajani K. Inducible clindamycin resistance among clinical isolates of staphylococci. Indian J Path Microbiol 2009;52:49-51.

16. Patel M, Waites KB, Moser SA, Cloud GA, Hoesley CJ. Prevalence of inducible clindamycin resistance among community and hospital-associated Staphylococcus aureus isolates. J Clin Microbiol 2006;44:2481-4.

How to cite this article: R, Saha A, N, Krishnamurthy V. Inducible clindamycin resistance in Staphylococcus aureus isolated from nursing and pharmacy students. J Lab Physicians 2011;3:89-92

Source of Support: Nil. Conflict of Interest: None declared.

\section{Author Help: Online submission of the manuscripts}

Articles can be submitted online from http://www.journalonweb.com. For online submission, the articles should be prepared in two files (first page file and article file). Images should be submitted separately.

\section{1) First Page File:}

Prepare the title page, covering letter, acknowledgement etc. using a word processor program. All information related to your identity should be included here. Use text/rtf/doc/pdf files. Do not zip the files.

\section{2) Article File:}

The main text of the article, beginning with the Abstract to References (including tables) should be in this file. Do not include any information (such as acknowledgement, your names in page headers etc.) in this file. Use text/rtf/doc/pdf files. Do not zip the files. Limit the file size to $1024 \mathrm{~kb}$. Do not incorporate images in the file. If file size is large, graphs can be submitted separately as images, without their being incorporated in the article file. This will reduce the size of the file.

3) Images:

Submit good quality color images. Each image should be less than $4096 \mathbf{~ k b ~ ( 4 ~ M B ) ~ i n ~ s i z e . ~ T h e ~ s i z e ~ o f ~ t h e ~ i m a g e ~ c a n ~ b e ~ r e d u c e d ~ b y ~}$ decreasing the actual height and width of the images (keep up to about 6 inches and up to about $1800 \times 1200$ pixels). JPEG is the most suitable file format. The image quality should be good enough to judge the scientific value of the image. For the purpose of printing, always retain a good quality, high resolution image. This high resolution image should be sent to the editorial office at the time of sending a revised article.

4) Legends:

Legends for the figures/images should be included at the end of the article file. 